When more than three errors are combined by method (3), the departure from the correct estimate is so slight that it can be ignored; but the overestimation by formula (1) is serious in all cases.

The essential point is this. If the probable error of a variable directly measured is calculated from the standard deviation of repeated measurements (assumed normally distributed), equation (1) may be used to calculate the probable error of a linear function of such variables. On the other hand, if the direct measurements are not repeated but have their probable errors estimated from the working intervals, equation (1) will over-estimate the probable error of the calculated result.

When the magnitude of the scale error differs among the variables, formula (5) must be modified, and the resultant probable error depends on the relative magnitudes of the scale errors. The net result is that equation (3) will not be far out when the scale errors are of about the same magnitude; but when they differ widely, the largest dominates the precision of the result and the rest may be ignored.

It should be noted again that these difficulties arise only when experimenters use 'probable' errors, now generally discarded in applied statistics. It will be a welcome reform in the 'exact' sciences when standard deviations and standard errors are accepted as conventional.

Section of Mathematical Statistics,

Council for Sciontific and Industrial Research, South Melbourne, S.C.4. July 16.

1 "Dict. App. Phys.", 3, The Combination of Observations, 649. 2 Silberstein, L., Phil. Mag., 35, 395 (1944).

${ }^{8}$ Gibbs, R. W. M., "The Adjustment of Errors in Practical Science", 8 (Oxford University Press, 1929).

\section{Relationship Between the Dissociation Constants of Unsymmetrical Dicarboxylic Acids}

The correlation of the first and second dissociation constants of symmetrical dicarboxylic acids with the distance apart of the ionizing groups is well known. An experimentally convenient correlation has not previously been proposed for unsymmetrical acids. For symmetrical acids the relationship may be represented by the equation

$$
\log _{10} \frac{K_{a^{\prime}}}{\delta K_{a^{\prime \prime}}}=\frac{N_{0} \varepsilon^{2}}{2 \cdot 303 R T D E r^{\prime}}
$$

where $K_{a}^{\prime}$ and $K_{a}$ " are respectively the first and second measured thermodynamic dissociation const ants, $\delta$ is a symmetry number (in this case 4 ), $N_{0}$ the Avogadro number, $\varepsilon$ the electronic charge, $R$ the gas constant, $T$ the absolute temperature and $D_{E}$ the effective dielectric constant for the space between the two ionizing groups separated by the distance $r$. For unsymmetrical acids a solution of the problem may be obtained by the following considerations.

In the case of any unsymmetrical dicarboxylic acid $\mathrm{H} A_{1} A_{2} \mathrm{H}$ we write

$$
K=\frac{a_{\mathrm{H}}+\cdot\left[\mathrm{H} A_{1} A_{2}-1 \cdot f_{-}\right.}{\left[\mathrm{H} A_{1} A_{2} \mathrm{H}\right] \cdot f_{0}} \text { and } K_{a}^{\mathrm{II}}=\frac{a_{\mathrm{H}}+\cdot\left[A_{1} A_{2} \mathrm{H}-\right] \cdot f_{-}}{\left[\mathrm{H} A_{3} A_{2} \mathrm{H}\right] \cdot f_{0}}
$$

for the thermodynamic dissociation constants corresponding to the two alternative steps for the first dissociation; and

$$
K_{a}{ }^{\mathrm{IT}}=\frac{a_{\mathrm{H}}+. \cdot\left[A_{2} A_{2}=\right] \cdot f_{\cong}}{\left[\mathrm{H} A_{1} A_{2}-\right] \cdot f_{-}} \text {and } K_{a^{\mathrm{IV}}}^{\mathrm{IV}}=\frac{a_{\mathrm{H}}+\cdot\left[A_{1} A_{8}=\right] \cdot f_{\text {长 }}}{\left[A_{1} A_{2} \mathrm{H}-\right] \cdot f-}
$$

for the corresponding two alternative routes for the second dissociation. In these expressions $f_{0}, f_{-}$and $f_{=}$ are the appropriate activity coefficients for the un. dissociated acid, for the monovalent anions and for the divalent anion respectively.

Now if the unsymmetrical acid be subjected to potentiometric titration we have, for the addition of $B$ equivalents of strong base,

$$
\begin{aligned}
& A=\text { molarity of the acid }=\left[\mathrm{H}_{1} A_{2} \mathrm{H}\right]+\left[\mathrm{H} A_{1} A_{2}-\right]+ \\
& {\left[A_{1} A_{2} \mathrm{H}-\right]+\left[A_{1} A_{2}=\right] \text { and }} \\
& B+[\mathrm{H}+]=\left[\mathrm{H} A_{1} A_{2}-\right]+\left[A_{1} A_{2} \mathrm{H}-\right]+2\left[A_{1} A_{2}=\right]+[\mathrm{OH}-] .
\end{aligned}
$$

If we then define

$\alpha=B+\left[\mathrm{H}^{+}\right]-[\mathrm{OH}-]=\left[\mathrm{H}_{1} A_{2}-\right]+\left[A_{1} A_{2} \mathrm{H}^{-}\right]+2\left[A_{1} A_{2}=\right]$ $\beta=A-B-[\mathrm{H}+]+[\mathrm{OH}-]=\left[\mathrm{H} A_{1} A_{2} \mathrm{H}\right]-\left[A_{1} A_{2}=\right]$ and $\gamma=2 A-B-[\mathrm{H}+]+[\mathrm{OH}-]=2\left[\mathrm{H} A_{1} A_{2} \mathrm{H}\right]+$

$$
\left.\left[A_{1} A_{2} A_{2}\right]+\right]+\left[A_{1} A_{2} \mathrm{H}-\right]
$$

it is readily shown that

$$
\begin{aligned}
& a_{\mathrm{H}}+\varepsilon \cdot\left(\frac{a}{\gamma}\right) \cdot \frac{f_{\equiv}}{f_{0}}=\left(K_{a^{\mathrm{I}}}+K_{a^{\mathrm{I}}}\right) \cdot a_{\mathrm{H}}+\cdot\left(\frac{\beta}{\gamma}\right) \cdot \frac{f_{=}}{f_{-}}+ \\
& \frac{\left(\boldsymbol{K}_{a^{T}}+\boldsymbol{K}_{a}^{\mathrm{IT}}\right)\left(\boldsymbol{K}_{a^{\mathrm{IIT}}} \cdot \boldsymbol{K}_{a^{\mathrm{IV}}}\right)}{\left(\boldsymbol{K}_{a^{\mathrm{III}}}+\boldsymbol{K}_{a^{\mathrm{IV}}}\right)}
\end{aligned}
$$

The constant term in this equation may be simplified by the considerations that

$$
K_{a}^{\mathrm{I}} / K_{a}^{\mathrm{IV}}=\exp N_{0} \varepsilon^{2} / R T D_{E^{2}} \text { and } K_{a}^{\mathrm{I}} / K_{a}^{\mathrm{II}}=\exp N_{0} \varepsilon^{2} / R T D_{E} r,
$$

where the symbols have the significance previously employed. The equation then reduces to

$$
\begin{aligned}
& a_{\mathrm{H}}{ }^{2} \cdot\left(\frac{\alpha}{\gamma}\right) \cdot \frac{f_{=}}{f_{0}}=\left(K_{a^{2}}+K_{a}^{\mathrm{II}}\right) \cdot a_{\mathrm{H}}+\cdot\left(\frac{\beta}{\gamma}\right) \cdot \frac{f_{\equiv}}{f_{=}}+ \\
& K_{a^{1} K_{a}}{ }^{\mathrm{II}} \cdot \exp -N_{0} E^{8} / R T D_{E^{r}} \text {. }
\end{aligned}
$$

Clearly this may be plotted as a linear equation, and if either $K_{a}{ }^{\mathrm{I}}$ or $K_{a} \mathrm{rI}$ be known, then the electrostatic term $\exp -N_{0} \varepsilon^{2} / R T D_{E} r$ may be evaluated and used for calculation of $r$. For this purpose it is only necessary to determine the dissociation constant of one of the mono-methyl esters, say, of the acid.

If $K_{a}{ }^{\mathrm{I}}=K_{a} \mathrm{II}$ and $K_{a}{ }^{\mathrm{III}}=K_{a}{ }^{\mathrm{IV}}$, that is, if the acid be symmetrical, it is readily shown that the equation reduces to a form which has been successfully em. ployed by Speakman ${ }^{I}$ for symmetrical dicarboxylic acids.

Application of the equation for unsymmetrical acids to problems in molecular structure will be reported elsewhere.

I thank Prof. H. V. A. Briscoe for his interest in these derivations.

\section{H. R. BARTON}

(I.C.I. Fellow)

Imperial College of Science and Technology, London, S.W.7.

Aug. 8.

${ }^{1}$ Speakman, J. C., J. Chem. Soe., 855 (1940).

\section{Phenazine Synthesis}

Contrnurng the researches of Clemo and Mcllwain ${ }^{1}$ on the structure of the pigment of Chromobacterium iodinum, we are engaged in the synthesis of phenazines. In view of the recent communication of Slack and Slack ${ }^{2}$, describing the preparation of $1: 2$ dimethoxyphenazine, we wish to put on record an independent synthesis using the method of Clemo and McIlwain ${ }^{3}$. 